This item was submitted to Loughborough's Institutional Repository (https://dspace.lboro.ac.uk/) by the author and is made available under the following Creative Commons Licence conditions.

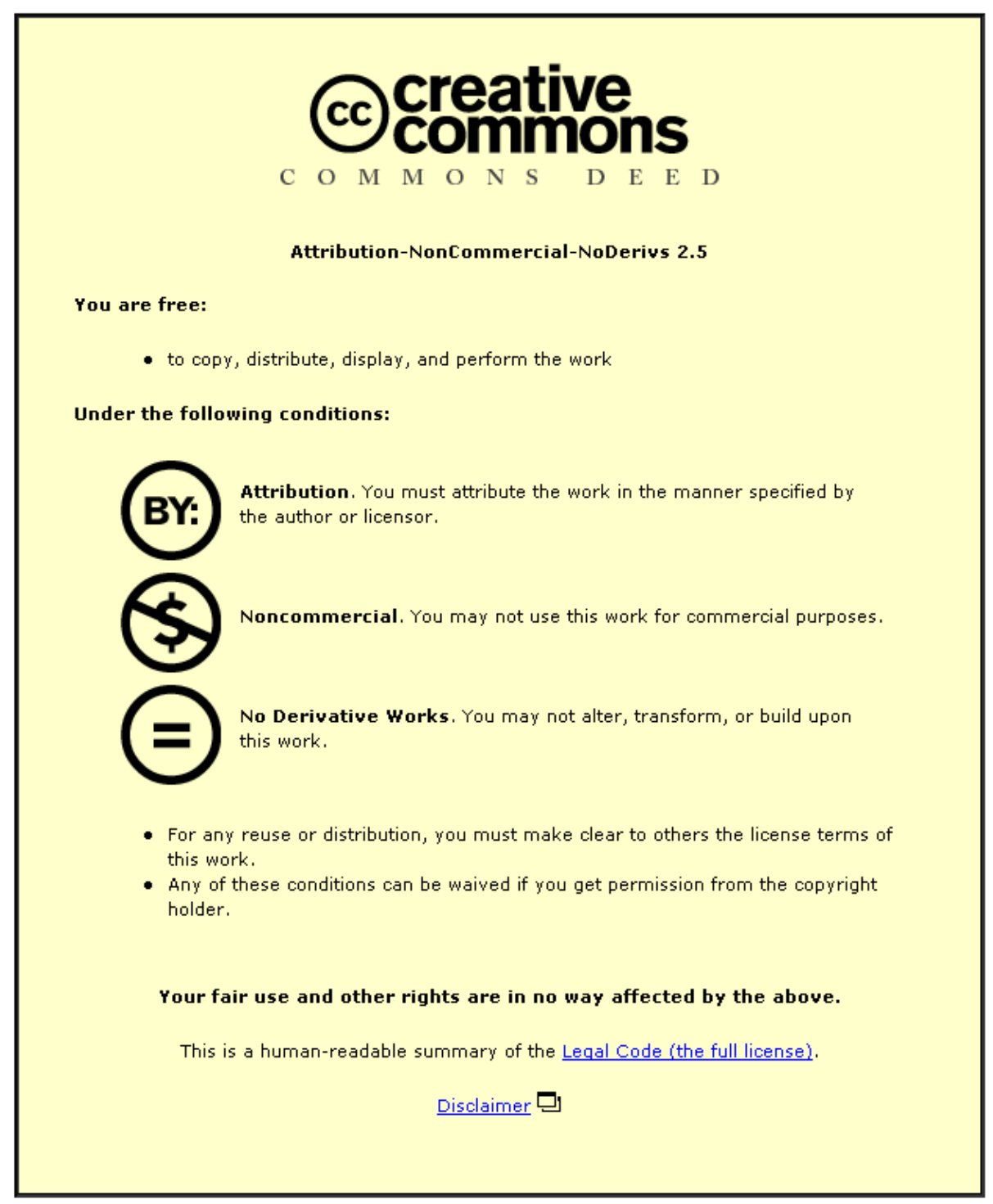

For the full text of this licence, please go to: http://creativecommons.org/licenses/by-nc-nd/2.5/ 


\title{
Airline Strategies for Aircraft Size and Airline Frequency with changing Demand and Competition: A simultaneous equations approach for traffic on the north Atlantic.
}

\author{
D.E.Pitfield, R.E.Caves and M.A.Quddus \\ Transport Studies Group \\ Department of Civil and Building Engineering \\ Loughborough University \\ Loughborough \\ Leics. LE11 3TU \\ UK \\ Email: D.E.Pitfield@lboro.ac.uk
}

\begin{abstract}
Airport planners need to know the forecast demand on the facilities provided airside at airports. For this they need to know how airlines will deal with traffic in terms of the size of aircraft and frequency of service. In response to increasing demand, airlines may increase capacity by increasing the frequency of flights or they may choose to increase aircraft size. This may yield operating cost economies. If the airports they operate from are capacity constrained they will be limited in the extent that they can change frequency which will limit their ability to compete with the number of frequencies offered. Consequently, these airports are excluded as are major hubs as frequencies will be influenced by connecting passengers. Routes are identified on the north Atlantic that can be analysed and conclusions are suggested on the basis of three stage least squares estimates for pooled time series-cross section data. An increase in passengers on the whole will result in a larger increase in frequency than in aircraft size but the impact of competition does not yield significant results due to the strategy of excluding certain categories of airport.
\end{abstract}




\section{Introduction}

Airport planners, amongst other concerns, are charged with making recommendations on airside investments at airports so as to facilitate traffic, for example, on the use of runway slots and the size and number of aircraft stands. For this, they require forecast passenger and cargo volumes. If, as in many cases, cargo is belly-hold, then the planning concerns passenger movements. However, airlines can and do choose to adjust the size of the aircraft in their fleets and change the frequency of the service that they offer. In addition, on some routes, the advent of competition in the form of an additional carrier responding to demand opportunities can affect the aircraft size and the frequency of the incumbent airlines. All the airlines will, after entry, continue to adjust size and frequency.

An airline in a monopoly position on a route, with the expectation of increased traffic in the coming year, can adopt the strategy of catering for the increase by offering increased frequency of service or keep the frequency constant but increase the aircraft size. The ability to adopt the latter course depends on the airline's ability to manage its fleet of aircraft to allow this and to deter entry and where it can achieve these ends, it will benefit from lower seat costs from the larger aircraft.

However, if the airline is in a duopolistic, oligopolistic or contestable market, its response will be to increase the frequency to cover the increased demand and perhaps to increase it beyond this level so as to both manage and gain market share. Again, it is presumed the airline can manage its fleet to allow it to operate smaller aircraft. 
It is this trade-off between aircraft size and frequency that this paper is trying to examine empirically for the long haul sector following earlier efforts by Pitfield and Caves (2000a, 2000b) and more recent research by Givoni and Rietveld (2007). Consequently, modelling this trade-off at an airport level provides vital information to planners on required airside facilities, given forecast traffic, airline behaviour and the degree of competition.

A simultaneous equations approach is needed as there is two way causation between demand and frequency and aircraft size and any simple equation model that ignores this will produce biased and inconsistent estimates. The north Atlantic was chosen as it represents a vibrant market with a variety of serving airlines, often in a competitive environment. Observers might agree that it is the world's largest and most interesting international market. However, airports are excluded if they are slot constrained, such as New York John F Kennedy (JFK) and London Heathrow (LHR). This limits the total number of slots although individual airlines may still be able to manage their own usage . Also excluded are major hub airports, such as Chicago O’Hare (ORD) and Paris Charles de Gaulle (CDG) where frequencies will be greater (Brueckner and Zhang, 2001) and reflect connecting passengers. This will bias the relationship with origin-destination passenger numbers. The questions remain as to what extent long haul services can adjust aircraft size downwards and retain the necessary payload and range and whether the airlines studied have a variety of aircraft types. In addition, can sufficient airport pairs be identified that are not subject to these constraints? 


\section{Data}

Before data is examined from 1990 for nine routes linking European airports to airports in the USA using Bureau of Transportation Statistics' (Bureau of Transportation Statistics) origin-destination data on passenger numbers, frequency offered and aircraft size, consideration was given to how best to study competition on the basis of frequency and aircraft size. Routes within Europe for most of the period for which data is readily available were governed by bilaterals between the countries that limited the number of carriers. Indeed, for many thinner routes, only one carrier operated. However, consistent European data are not available from a single source for the study period and, in any case, the startling phenomena within European air traffic for at least the last 10 years or so has been the price competition between lowcost carriers and legacy carriers where observed changes in pricing strategies have been seen as well as competitive impacts on market share (see Pitfield, 2005, 2007). For these reasons, therefore, a focus on the north Atlantic was chosen as it has always been competitive and has not been blessed with a low-cost carrier, until very recently ${ }^{1}$ and consistent passenger and frequency data can be obtained online from 1990 (Bureau of Transportation Statistics) giving a long time series. Data for non-stop routes between airports was examined as it was felt that this would capture most of the traffic and allow the analysis to be conducted ${ }^{2}$.

From Germany, service from Munich (MUC) to Miami (MIA) along with Dusseldorf (DUS) to Los Angeles (LAX) is covered. From Italy, Milan Malpensa (MXP) service to LAX is examined along with service to Boston (BOS) and Washington Dulles

\footnotetext{
${ }^{1}$ New carriers like Maxjet, Silverjet and Eos undercut standard business fares before their demise.

2 There is very little indirect (one or two-stop traffic) on these airport pairs.
} 
(IAD). Finally, from the UK, services from London Gatwick (LGW) to BOS, MIA and Orlando (MCO) are examined along with Manchester (MAN) to MCO. It is difficult to choose routes that completely satisfy the criteria set out as Lufthansa hubbed from MUC from 2001 where a new terminal for the Star Alliance opened in 2003; MXP was the primary hub for Alitalia intercontinental flights with plans to reduce this presence in 2007; British Airways hubs at LGW and United has a minor hub at LAX and a major one at IAD. American hubs at MIA. In addition, the services to MCO are dominated, before the advent of Virgin, by charter carriers who may not display the characteristics that this paper is trying to illustrate and capture and there are capacity problems at LGW and DUS. In addition, it could be argued that services in some cases are available from adjacent airports for the routes identified. The only case of this of relevance, in effect, are LGW and LHR, as is seen particularly later in section 5, as well as the adjacent airports in Orlando, Florida which are dealt with in section $3^{3}$.

These routes were chosen to try and cover the initial criteria and represent a variety of stage lengths and degrees of competition. It was felt that 1990 was an appropriate start date for the UK because this history encompasses the dismantling of the London area distribution rules and the relaxation of UK regional airport north Atlantic access ${ }^{4}$. For the mainland Europe airports, the routes were subject to their countries bilaterals with the USA before open skies. This selection also gives a sufficient time series of a maximum of 17 observations for each route and 153 pooled observations. Some routes are not operated for all of the 17 years examined.

\footnotetext{
${ }^{3}$ Service was only available to both LGW and LHR for BOS and MIA.

${ }^{4}$ UK regional airports are still constrained in north Atlantic access by demand in their catchment areas, which will be influenced by the frequency they can offer. Other influences are runway length as well as their operational regularity in terms of Cat 2 or 3 capability. Airlines may also deterred by airport charges.
} 
These data are shown in the following Figures. Figure 1 shows passengers by route from 1990. It can be seen that the thinnest routes may well not provide the incumbent airline with the ability to substitute between frequency and aircraft size as their choice is constrained. In addition, more certainly, they do not attract competitors as the economic rewards are low.

Figure 2 shows the frequency offered by route and Figure 3 Aircraft Size. It seems that there are fluctuations in the trade-off on the busier routes and this is reflected directly in Figure 4. Figure 5 displays frequency against passengers and appears to show frequency growing more rapidly at lower traffic levels and later being traded for size, the change being around 400,000 passengers, which seems sensible ${ }^{5}$.

Table 1 shows the variety of equipment types available to the airlines serving the routes for four selected years, 1996, 1999, 2002 and 2005. For most airlines it is clear that there is a variety of equipment that they could chose. Although some of the types available are not suitable for transatlantic journeys, most of the larger carriers had a variety of appropriate Airbus and Boeing aircraft in their fleets including A320, A321, A330, A340 and various series of Boeing 747, 757, 767, 777 as well as older McDonnell Douglas Aircraft earlier in the period examined.

\footnotetext{
${ }^{5}$ Of course, airlines will use larger aircraft not just for competitive reasons.
} 
Table 1: Equipment Type available to Airlines by route for selected years.

\begin{tabular}{|c|c|c|c|}
\hline Year & Routes & Airlines & $\begin{array}{l}\text { Equipment } \\
\text { Types } \\
\text { Available } \\
\text { on Non- } \\
\text { Stop } \\
\text { Routes }\end{array}$ \\
\hline \multirow[t]{9}{*}{1996} & A - LGWBOS & Virgin Atlantic (VS) & 7 \\
\hline & B - LGWMIA & VS, British Airways (BA) & 7,35 \\
\hline & C - LGWMCO & $\mathrm{BA}, \mathrm{VS}$ & 35,7 \\
\hline & D - MANMCO & Laker Airways (6F), VS, BA & $1,7,35$ \\
\hline & E - DUSLAX & LTU International Airways (LT) & 11 \\
\hline & F - MUCMIA & $\begin{array}{l}\text { Lufthansa German Airlines (LH), } \\
\text { Lauda Air (NG) }\end{array}$ & 24,3 \\
\hline & G - MXPBOS & - & - \\
\hline & H - MXPIAD & United Airlines (UA) & 29 \\
\hline & I - MXPLAX & Alitalia (AZ) & 27 \\
\hline \multirow[t]{9}{*}{1999} & A & VS, BA & 5,33 \\
\hline & $\mathrm{B}$ & BA, VS, American Airlines (AA) & $33,5,22$ \\
\hline & $\mathrm{C}$ & $\mathrm{BA}, \mathrm{VS}$ & 33,5 \\
\hline & $\mathrm{D}$ & VS & 5 \\
\hline & $\mathrm{E}$ & $\mathrm{LT}$ & 12 \\
\hline & $\mathrm{F}$ & NG & 8 \\
\hline & G & $\mathrm{AZ}$ & 27 \\
\hline & $\mathrm{H}$ & UA & 30 \\
\hline & I & - & - \\
\hline \multirow[t]{9}{*}{2002} & A & Delta Air Lines (DL) & 20 \\
\hline & B & VS & 6 \\
\hline & $\mathrm{C}$ & VS, BA & 6,29 \\
\hline & $\mathrm{D}$ & VS & 6 \\
\hline & $\mathrm{E}$ & $\mathrm{LT}$ & 5 \\
\hline & $\mathrm{F}$ & - & - \\
\hline & G & $\mathrm{AZ}$ & 23 \\
\hline & $\mathrm{H}$ & UA & 16 \\
\hline & I & - & - \\
\hline \multirow[t]{9}{*}{2005} & A & - & - \\
\hline & B & - & - \\
\hline & $\mathrm{C}$ & BA, VS & 25,4 \\
\hline & $\mathrm{D}$ & VS & 4 \\
\hline & $\mathrm{E}$ & $\mathrm{LT}$ & 8 \\
\hline & $\mathrm{F}$ & LH, LT & 22,8 \\
\hline & G & $\mathrm{AZ}$ & 18 \\
\hline & $\mathrm{H}$ & $\mathrm{AZ}$ & 18 \\
\hline & I & - & - \\
\hline
\end{tabular}




\section{Model and Variable Specification}

To deal with the simultaneity in the relationships it was necessary to specify the following models of frequency, aircraft size and passengers, where the primary interest is in the first two named models with the passenger model included to avoid the two-way causation bias. The simultaneous-equation models can be presented as:

$$
\begin{aligned}
& \ln F_{i t}=\alpha_{F}+\beta_{p} \ln P_{i t}+\beta_{s} \ln S_{i t}+\beta_{1} \ln F_{i, t-1}+\beta_{2} \ln C_{i t}+\beta_{3} \ln T_{i t}+\boldsymbol{\theta D}+u_{i t 1} \\
& \ln P_{i t}=\alpha_{P}+\beta_{F} \ln F_{i t}+\beta_{s} \ln S_{i t}+\beta_{1} \ln P_{i, t-1}+\beta_{2} \ln C_{i t}+\beta_{3} \ln T_{i t}+\boldsymbol{\theta D}+u_{i t 2} \\
& \ln S_{i t}=\alpha_{S}+\beta_{F} \ln F_{i t}+\beta_{P} \ln P_{i t}+\beta_{1} \ln D i s_{i}+\beta_{2} \ln C_{i t}+\beta_{3} \ln T_{i t}+\boldsymbol{\theta D}+u_{i t 3}
\end{aligned}
$$

where,

$F_{i t}=$ Frequency of aircraft in year $t$ for route $i$

$F_{i, t-1}=$ Frequency of aircraft in the previous year $t-1$ for route $i$

$P_{i t}=$ Passenger numbers in year $t$ for route $i$

$P_{i, t-1}=$ Passenger numbers in the previous year $t-1$ for route $i$

$S_{i t}=$ Aircraft size in year $t$ for route $i$

$C_{i t}=$ Competition between airlines in year $t$ for route $i$

Dis $_{i}=$ Distance (Great Circle) for route $i$

$T_{i t}=$ Trend variable

$\boldsymbol{D}=$ A vector of dummy variables representing routes

$u_{i t 1}, u_{i t 2}$, and $u_{i t 3}$

$\alpha^{\prime} s, \beta^{\prime} s$ and $\theta^{\prime} s$ are the model parameters to be estimated

Logarithmic transformations of variables are used as it is generally held that the relationship between the variables is not linear. Wei and Hanson (2005) are of this view but contrast Button and Drexler (2005). Thought was given to the specification of a technology variable to reflect the change from Tri-Stars and DC10s to Boeing 777s; it was decided that this complicate the model specification and the effects of the transition might well be captured in the variables already included.

It is noticeable that there are three endogenous variables $(F, P$, and $S)$ in the simultaneous-equation models presented in equation (1). The other variables, 
including the lagged endogenous variables such as lagged frequency $\left(F_{t-1}\right)$ and lagged passenger numbers $\left(P_{t-1}\right)$, are the exogenous (or predetermined) variables. The endogenous and exogenous variables of equation (1) are carefully selected based on a priori or theoretical grounds. In addition to this, two statistical tests could be conducted: (1) the Hausman specification test for simultaneity to detect the presence of simultaneity and (2) the Hausman specification test for endogeneity to determine whether a group of variables is endogenous. It can be seen from equation (1) that each equation meets both order and rank conditions (see Greene, 2003) and therefore, the equations are identified and the model parameters can be estimated for this simultaneous-equation model.

The frequency model, where this is used to manage market share (Janic, 1997), suggests that frequency is related to passenger numbers, aircraft size, previous frequency, a competition term plus trend and route dummy variables to identify any unique route features. The respective sign expectations for the variables excluding the trend and dummies are positive, frequency increases as passenger numbers increases; negative, as frequency will fall as aircraft size increases and either positive or negative as there is no a priori expectation other than that current practice will guide future practice. For the competition term it would be expected to be positively related to the number of carriers as increasing competition would be through increased frequency. The sign expectations are reversed when the Hirschman-Herfindahl Index (HHI) is used as when this increases there is less competition ${ }^{6}$. The trend term will indicate what is happening to frequency over time.

\footnotetext{
${ }^{6}$ Market shares in the calculations in this paper are measured in percentages rather than proportions.
} 
The passenger model shows its simultaneous dependence on frequency, aircraft size, previous passenger numbers and competition plus the trend and dummy variables. It is the simultaneity here that necessitates the use of an estimation procedure that will not give biased and inconsistent results as would OLS. This model shows that both frequency and aircraft size have some dependence on past passenger numbers which reflects airline decision making where the actual lag may reflect the change between the summer and winter schedules, about six months. It would be expected that passengers are positively related to frequency; for aircraft size to allow more passengers to be carried and so be positive and for the relationship with past passenger numbers, along with the trend term, to indicate movements in the series over time. More competition in the case of more carriers should allow more passengers as well as less concentration.

The aircraft size equation shows the simultaneous dependence on frequency, passengers, distance between airports studied, competition and the trend and dummies. Aircraft size and frequency should be negatively related whereas size and passengers are again positively related. Increased distance might result in larger aircraft being used to achieve the payload and range although changes in aircraft technology suggest this might be less important than in the past. Competition, however it is measured, should decrease aircraft size so more carriers results in smaller aircraft as does a smaller HHI. The trend will indicate what has been happening over the period studied.

Competition was initially measured as the number of principal carriers on the route. If this had been significant for the sample studied here the interpretation would have 
been straightforward. However, as the German and Italian routes generally had little competition, it seemed that this specification might be insignificant for this reason. When the four UK routes were examined alone, however, the results, surprisingly, failed to improve. Consequently, the HHI was calculated to better represent concentration. This is a standard way of examining competition and was initially used in a proposed soft drinks case merger in the US (Stiglitz, 1993). Indeed, it is a standard means of measuring the acceptability of mergers and alliances and of their impact on market share and competition.

The index is given by,

$$
\mathrm{HHI}=\mathrm{MS}_{1}{ }^{2}+\mathrm{MS}_{2}{ }^{2}+\mathrm{MS}_{3}{ }^{2}+\mathrm{MS}_{4}{ }^{2}+\cdots \cdots \cdots \cdots \cdot \mathrm{MS}_{\mathrm{n}}{ }^{2}
$$

where $\mathrm{MS}_{\mathrm{i}}{ }^{2}$ is the market share of individual firms $\mathrm{i}$ (airlines here) and it is used by the UK Office of Fair Trading, the US Department of Justice and the US Federal Trade Commission. Values of HHI of less than 1000 are said to represent an unconcentrated and very competitive market whereas market values greater than 1800 represent concentration and a relative absence of competition. If mergers and alliances were to raise the HHI above 1800 then the merger would be challenged however when the statistic is already above 1800, any proposed merger should not result in an increase of more than 100 . The maximum value of 10,000 is reached here for some routes indicating monopoly. The simple correlation of this HHI statistic with the competition variable as measured by the number of principal carriers is -0.917 falling to -0.836 if the carriers at the adjacent Sanford airport, Florida are counted in the two 
MCO cases. For the routes to BOS and MIA from LGW, the HHI also takes into account the carriers and their market share at LHR.

Literature suggests that there are two approaches to estimate simultaneous-equation models (e.g., Greene, 2003): (1) single-equation methods or limited information methods such as two Stage Least Squares (2SLS), (2) system methods or full information methods such as three Stage Least Squares (3SLS). In the former method, each equation in the system of simultaneous equations is estimated independently taking into account any restrictions placed on that equation without considering the restrictions on the other equations in the system. In the system methods, all the equations in the models are estimated simultaneously by taking into account all restrictions on such equations.

Greene (2003) pointed out that the system methods are to be preferred to singleequation method. If interest lies in a particular equation of a system, then Wooldridge (2001) suggests that 2SLS is more robust and consistent provided that the equations are correctly specified. Although 2SLS is computationally cheaper, Belsley (1988) found that coefficients estimated by 3SLS are more efficient (asymptotically) than 2SLS, especially for the case of a small sample dataset. This is true given that all equations in the system are correctly specified. Otherwise, the specification error of one or more equations is transmitted to the rest of the system. Gujrati (2003) suggests the use of 2SLS when there are no lagged endogenous variables and the sample size is large. Since the sample dataset is small and there are lagged endogenous variables, the use of 3SLS is more appropriate. In addition, the interest is in all equations of the system and as there is confidence that the equations are not miss-specified, as 
suggested by the specification test, this reinforces the use of 3SLS. The 3SLS estimation procedure is conducted by first obtaining 2SLS estimates of the equation system which are calculated using endogenous variables regressed against all exogenous variables including lagged endogenous variables. The 2SLS estimates are then applied to estimate the equation system's stochastic error terms which are subsequently used to estimate the contemporaneous correlation among them. At the final stage, a generalized least-squares (GLS) estimation method is applied to estimate model coefficients using the estimated contemporaneous variance-covariance matrix of error terms (STATA, 2006).

\section{Pooled Results}

The Hausman specification tests for both simultaneity and endogeneity were conducted using the data. The results suggest that there is a presence of simultaneity (at 95\% confidence level) in the equations of the system meaning that the use of OLS would result in both biased and inconsistent coefficient estimates. The results also imply that the group of variables such as frequency, passenger numbers and aircraft size are endogenous in nature (again at the 95\% confidence level). A further statistical test, the Ramsey's RESET test (Ramsey, 1969), was conducted to see whether there is any specification error. The results indicate that the log-linear version of these equations as shown in (1) is not miss-specified and the use of 3SLS is appropriate.

Two models were estimated using 3SLS from all the available data (a total of nine routes) comprising a total of 121 valid observations. Nine observations were lost due to the use of lagged endogenous variables in the models. In the first model (see Table 2), the variable representing competition among airlines is the number of principal 
carriers operating the route. In the second model presented in Table 3, the competition variable is taken as HHI. Since only a little competition is evident among non-UK routes, two additional models were estimated for the data from 4 UK-based routes. The results are presented in Table 4 (in which the competition variable is the principal number of carriers) and Table 5 (in which the competition variable is $\mathrm{HHI}$ ). To take into account the impact of routes, if any, a series of dummy variables (i.e., $\boldsymbol{D}$ ) for routes was created and included in all models. The coefficients of these dummy variables should be interpreted relative to the reference route (LGW-BOS) ${ }^{7}$. An exponential trend variable (i.e., $\boldsymbol{T}$ ) was also introduced in all models to account for the time effect. Since the log-linear version of the equations was used, the coefficient values represent elasticities rather than slope-coefficients.

The frequency model using the HHI measure of competition is shown in Table 3. This model is slightly preferred as although there are no differences of note in $R^{2}$ the $t$ statistics indicate that the more variable and powerful HHI measure of competition is approaching significance and implies, through further calculations at the sample means, that an additional 289 passengers $^{8}$ call forth one new frequency and that frequency falls by $0.11 \%$ ceteris paribus with a percent change in the trend variable ${ }^{9}$. The aircraft size model shows that aircraft size increases when an extra 451 passengers are present and that the trend here is a decline of $0.14 \%$. However, the

\footnotetext{
${ }^{7}$ Any route may be taken as the reference route and subsequent calculations can reveal the results for all routes whichever is selected.

${ }^{8}$ Since the model is a log-log model, the slope coefficient is calculated from the following equation: slope $=\beta\left(\frac{\bar{Y}}{\bar{X}}\right)$

${ }^{9}$ Remembering the earlier conclusion based on Figure 5, suggests that after 400,000 passengers and some 26 weekly frequencies that a trade would be made to aircraft size. The trend variable will be influenced by the impact of $9 / 11$ but as it captures this effect, the other relationships are not confounded by its influence.
} 
competition term is insignificant although it appears to be better than the alternative measure based on carriers, the results for which are shown in Table 2.

The coefficients in Tables 2 and 3 are direct estimates of elasticities so a one percent change in passengers results in an inelastic 0.94 percent increase in frequency in the HHI model whereas this same change in passengers results in 1.44 percent increase in aircraft size. The trade-off of interest is also shown. In the frequency model a one percent change in aircraft size causes a 0.89 percent fall in frequency whereas in the aircraft size model a one percent change in frequency causes a 1.61 percent fall in size. This can be clearly illustrated if it is supposed that there is a 10 percent increase in passengers, then the aircraft size model would predict a 14.4 percent increase in size. Simultaneously, the frequency model would predict a 9.4 percent increase in frequency and if this is fed into the size model a change in size of 15.1 percent is shown. That is, a 10 percent increase in passengers results in a 9.4 percent change in frequency and a net change in size of -0.7 percent, which seems reasonable. The impact is greater, on average, on frequency than on size, although individual airlines may have different strategies that constitute this average result.

The reference route is LGW-BOS and by comparison both MAN-MCO and DUSLAX have significantly lower frequencies. In addition, the MAN-MCO route also has significantly smaller aircraft than the reference case, but a larger number of passengers. These results reflect the leisure nature of the route and the way that it is approached by both legacy carriers and the carriers that work for tour operators. 
Tables 4 and 5 show the results for the UK routes using the number of carriers and the HHI as competition measures. It was hoped that this reduced sample would show empirical evidence of the impact of competition but unfortunately, it does not. Surprisingly, in addition, the trend variable is insignificant.

The results using the HHI measure are broadly comparable to those shown in Table 3 and where there are differences, it is unlikely that they will be instructive due to the relative weakness of the model compared to the results shown in Table 3. 
Table 2: 3SLS estimation results for all routes (Competition =carriers)

\begin{tabular}{|c|c|c|c|c|c|c|c|c|}
\hline Equation: Frequency & Coeff & t-stat & Equation: Passenger & Coeff & t-stat & Equation: Aircraft size & Coeff & t-stat \\
\hline In(Passenger numbers) & 0.9171 & 9.59 & In(Frequency) & 1.0215 & 3.29 & In(Passenger) & 1.4420 & 2.74 \\
\hline In(Aircraft size) & -0.7234 & -4.43 & In(Aircraft size) & 0.8146 & 5.15 & In(Frequency) & -1.6126 & -2.59 \\
\hline In(Carriers) & -0.0282 & -0.60 & In(Carriers) & 0.0383 & 0.62 & In(Carriers) & -0.0054 & -0.05 \\
\hline In(Trend) & -0.0873 & -4.90 & In(Trend) & 0.0842 & 1.68 & $\ln ($ Trend) & -0.1307 & -3.37 \\
\hline Route-specific dummies & & & Route-specific dummies & & & Route-specific dummies & & \\
\hline LGW - BOS & & & LGW - BOS & & & LGW - BOS & & \\
\hline LGW - MIA & -0.0636 & -1.41 & LGW - MIA & 0.0715 & 1.48 & LGW - MIA & -0.0715 & -0.77 \\
\hline MAN - MCO & -0.1304 & -2.37 & MAN - MCO & 0.1356 & 2.26 & MAN - MCO & -0.1656 & -1.51 \\
\hline LGW - MCO & -0.0711 & -0.95 & LGW - MCO & 0.1076 & 0.73 & LGW - MCO & -0.0772 & -0.86 \\
\hline MXP - LAX & 0.1027 & 1.55 & MXP - LAX & -0.1035 & -1.26 & MXP - LAX & 0.2978 & 0.57 \\
\hline MXP - BOS & -0.0369 & -0.41 & MXP - BOS & 0.0688 & 0.44 & MXP - BOS & 0.0727 & 0.19 \\
\hline MXP - IAD & -0.0133 & -0.20 & MXP - IAD & 0.0233 & 0.27 & MXP - IAD & 0.1048 & 0.25 \\
\hline MUC - MIA & 0.0375 & 0.42 & MUC - MIA & -0.0745 & -0.46 & MUC - MIA & 0.1281 & 0.38 \\
\hline DUS - LAX & -0.2348 & -1.97 & DUS - LAX & 0.1745 & 0.50 & DUS - LAX & -0.3015 & -0.98 \\
\hline
\end{tabular}


Table 3: 3SLS estimation results for all routes (Competition =HHI)

\begin{tabular}{|c|c|c|c|c|c|c|c|c|}
\hline Equation: Frequency & Coeff & t-stat & Equation: Passenger & Coeff & t-stat & Equation: Aircraft size & Coeff & t-stat \\
\hline In(Passenger numbers) & 0.9414 & \begin{tabular}{|l|}
7.97 \\
\end{tabular} & In(Frequency) & 0.8832 & 1.80 & In(Passenger) & 1.4351 & 2.25 \\
\hline $\ln ($ Aircraft size) & -0.8935 & -2.96 & In(Aircraft size) & 1.0638 & 2.46 & In(Frequency) & -1.6127 & -2.16 \\
\hline $\ln (\mathrm{HHI})$ & 0.0987 & 1.05 & $\mathrm{In}(\mathrm{HHI})$ & -0.1352 & -0.92 & $\ln (\mathrm{HHI})$ & 0.0548 & 0.48 \\
\hline In(Trend) & -0.1072 & -4.12 & In(Trend) & 0.0906 & 1.52 & In(Trend) & -0.1410 & -3.42 \\
\hline Route-specific dummies & & & Route-specific dummies & & & Route-specific dummies & & \\
\hline LGW - BOS & & & LGW - BOS & & & LGW - BOS & & \\
\hline LGW - MIA & -0.0686 & -1.42 & LGW - MIA & 0.0775 & 1.32 & LGW - MIA & -0.0640 & -0.81 \\
\hline MAN - MCO & -0.1434 & -2.65 & MAN - MCO & 0.1303 & 1.72 & MAN - MCO & -0.1780 & -2.14 \\
\hline LGW - MCO & -0.0790 & -0.98 & LGW - MCO & 0.1573 & 0.75 & LGW - MCO & -0.0717 & -0.89 \\
\hline MXP - LAX & -0.0059 & -0.05 & MXP - LAX & 0.0483 & 0.23 & MXP - LAX & 0.2606 & 0.52 \\
\hline MXP - BOS & -0.1863 & -0.94 & MXP - BOS & 0.3016 & 0.79 & MXP - BOS & 0.0148 & 0.04 \\
\hline MXP - IAD & -0.1483 & -0.91 & MXP - IAD & 0.2083 & 0.82 & MXP - IAD & 0.0525 & 0.13 \\
\hline MUC - MIA & -0.0221 & -0.22 & MUC - MIA & -0.0533 & -0.26 & MUC - MIA & 0.0893 & 0.30 \\
\hline DUS - LAX & -0.2926 & -2.30 & DUS - LAX & 0.1095 & 0.22 & DUS - LAX & -0.3443 & -1.31 \\
\hline Observations & \multicolumn{2}{|c|}{121} & Observations & \multicolumn{2}{|c|}{121} & Observations & \multicolumn{2}{|c|}{121} \\
\hline R-squared & \multicolumn{2}{|c|}{0.984} & R-squared & \multicolumn{2}{|c|}{0.981} & R-squared & \multicolumn{2}{|c|}{0.568} \\
\hline
\end{tabular}


Table 4 3SLS estimation for UK-based routes (competition = carriers)

\begin{tabular}{|c|c|c|c|c|c|c|c|c|}
\hline Equation: Frequency & \begin{tabular}{|l|l} 
Coeff & $t$ \\
\end{tabular} & t-stat & Equation: Passenger & Coeff & t-stat & Equation: Aircraft size & Coeff & t-stat \\
\hline In(Passenger numbers) & \begin{tabular}{|r|}
1.0010 \\
\end{tabular} & 5.95 & In(Frequency) & 0.9774 & 3.59 & In(Passenger) & \begin{tabular}{|l|}
1.1329 \\
\end{tabular} & 5.68 \\
\hline $\ln ($ Aircraft size) & -0.9293 & -3.66 & In(Aircraft size) & 0.9059 & 13.3 & In(Frequency) & -1.1655 & -5.26 \\
\hline $\ln$ (Carriers) & 0.0141 & 0.31 & In(Carriers) & -0.0152 & -0.34 & In(Carriers) & 0.0292 & 0.48 \\
\hline In(Lagged frequency) & -0.0188 & -0.2 & In(Lagged passenger) & 0.0336 & 0.2 & In(distance) & -0.0282 & -0.2 \\
\hline In(Trend) & -0.0053 & -0.17 & In(Trend) & -0.0004 & -0.01 & In(Trend) & -0.0110 & -0.47 \\
\hline Route-specific dummies & & & Route-specific dummies & & & Route-specific dummies & & \\
\hline LGW - BOS & & & LGW - BOS & & & LGW - BOS & & \\
\hline LGW - MIA & -0.1209 & -1.27 & LGW - MIA & 0.1248 & 1.33 & LGW - MIA & -0.1193 & -2.54 \\
\hline MAN - MCO & -0.0652 & -1.95 & MAN - MCO & 0.0661 & 2.13 & MAN - MCO & -0.0642 & -1.41 \\
\hline LGW - MCO & -0.0904 & -1.94 & LGW - MCO & 0.0889 & 2.22 & LGW - MCO & -0.0885 & -1.41 \\
\hline Observations & \multicolumn{2}{|c|}{57} & Observations & \multicolumn{2}{|c|}{57} & Observations & \multicolumn{2}{|c|}{57} \\
\hline R-squared & \multicolumn{2}{|c|}{0.979} & R-squared & \multicolumn{2}{|c|}{0.980} & R-squared & \multicolumn{2}{|c|}{0.727} \\
\hline
\end{tabular}

Table 5: 3SLS estimation for UK-based routes (competition = HHI)

\begin{tabular}{|c|c|c|c|c|c|c|c|c|}
\hline Equation: Frequency & Coeff & t-stat & Equation: Passenger & Coeff & t-stat & Equation: Aircraft size & Coeff & t-stat \\
\hline In(Passenger numbers) & 0.9975 & 4.11 & In(Frequency) & 0.9876 & 2.70 & In(Passenger) & 1.1067 & 5.83 \\
\hline $\ln ($ Aircraft size) & -0.9402 & -2.14 & In(Aircraft size) & 0.9211 & 9.35 & In(Frequency) & -1.1394 & -5.29 \\
\hline $\ln (\mathrm{HHI})$ & 0.0158 & 0.25 & $\ln (\mathrm{HHI})$ & -0.0144 & -0.27 & $\ln (\mathrm{HHI})$ & 0.0110 & 0.23 \\
\hline $\ln ($ Trend $)$ & -0.0146 & -0.37 & In(Trend) & 0.0104 & 0.14 & In(Trend) & -0.0216 & -0.87 \\
\hline Route-specific dummies & & & Route-specific dummies & & & Route-specific dummies & & \\
\hline LGW - BOS & & & LGW - BOS & & & LGW - BOS & & \\
\hline LGW - MIA & -0.1249 & -1.02 & LGW - MIA & 0.1278 & 1.12 & LGW - MIA & -0.1271 & -3.01 \\
\hline MAN - MCO & -0.0682 & -1.90 & MAN - MCO & 0.0692 & 2.23 & MAN - MCO & -0.0714 & -1.87 \\
\hline LGW - MCO & -0.1077 & -2.75 & LGW - MCO & 0.1072 & 3.07 & LGW - MCO & -0.1166 & -2.81 \\
\hline Observations & \multicolumn{2}{|c|}{57} & Observations & \multicolumn{2}{|c|}{57} & Observations & \multicolumn{2}{|c|}{57} \\
\hline R-squared & \multicolumn{2}{|c|}{0.979} & R-squared & \multicolumn{2}{|c|}{0.980} & R-squared & \multicolumn{2}{|c|}{0.740} \\
\hline
\end{tabular}




\section{A Micro Analysis by Selected Route - LGW-BOS}

The relationship between size and frequency can perhaps be better understood if a more detailed examination is made of particular cases. Rather than looking at the data for all years for all routes, years can be selected that show notable changes for particular routes and here LGW-BOS is examined to illustrate this as there seems to be evidence of competition. Examining percentage changes in frequency, aircraft size and passengers showed that at the beginning of the period both frequency and size increased as the route was developed and before the cessation of service, both decreased. The interesting cases are when they move in opposite directions and the largest cases are shown in Table 6. These are the result of the combined efforts of the incumbent airlines and their actions can be identified in more detail to explain each case shown. Overall, it suggests that airlines will react to changes in passenger demand by adjusting frequency more than size, which agrees with the earlier results. These percentages can be taken as indicators of elasticity for these notable changes.

Table 6: Percent changes for selected years, LGW-BOS

\begin{tabular}{|c|c|c|c|}
\hline Year & $\begin{array}{l}\text { Frequency } \\
\text { change (\%) }\end{array}$ & $\begin{array}{l}\text { Aircraft Size } \\
\text { change }(\%)\end{array}$ & $\begin{array}{l}\text { Passenger } \\
\text { change (\%) }\end{array}$ \\
\hline 1993-1994 & 10.31 & -16.55 & -8.33 \\
\hline 1995-1996 & -44.11 & 13.39 & -36.59 \\
\hline 1997-1998 & 55.71 & -20.73 & 29.97 \\
\hline $1998-1999$ & 15.62 & -9.99 & 3.40 \\
\hline 1999-2000 & -45.43 & 39.54 & -16.79 \\
\hline
\end{tabular}


From 1993 to 1994 Virgin Atlantic (VS) expanded frequency using Boeing 747’s and Northwest (NW) reduced aircraft size from the predominant use of $747 \mathrm{~s}$ to McDonnell Douglas DC10-40s, a smaller aircraft.

Between 1995-1996, the main overall influence was the withdrawal of NW. It had been operating McDonnell Douglas DC 10-30 and DC 10-40. In the configurations it used in 1995, these had 267-279 and 288 seats respectively. ${ }^{10}$ Average aircraft size became larger and frequency and passengers dropped on NW's withdrawal.

For 1997-1998 there is the contrasting case of increased frequency and a fall in aircraft size. VS maintained services with 747's. The increases in frequency come from the growth of service from American Airlines (AA) with Airbus 300s with some 192 seats. AA is competing on frequency. At the same time, British Airways (BA) is increasing its use of Boeing 777s and trading size for frequency at LHR.

From 1998 to 1999, whilst VS served a constant frequency of 747 services, AA increased frequency and reduced aircraft size from Airbus 300s to Boeing 767-200s.

For the last period identified, 1999-2000, AA withdrew the 767s it was now using at LGW to concentrate at LHR with larger Airbus 300s and VS continue to use 747s increasing their weight in the overall average at LGW.

It seems that even though LHR was slot-constrained, there would have been some merit in studying LGW and LHR together as BA seems to have had some flexibility

\footnotetext{
${ }^{10}$ All airlines operate aircraft with slightly differing seat configurations from time to time but an indication is required here rather than absolute figures.
} 
to assist it in its decisions on frequency and aircraft size when it introduced 777s on this route. Nevertheless, there are still instances of trading size for frequency that can be seen on LGW-BOS.

\section{Conclusion}

Despite the difficulties with data selection it appears that the econometric model is capable of reasonable interpretation. Increases in passenger numbers are, on average, likely to have a bigger influence on frequency than aircraft size and the micro-analysis supported this. This can be related to the findings on environmental implications reported in this issue by Givoni and Rietveld, (2009) as well as the alternative visions of Airbus and Boeing of future aircraft design (Mason, 2007). Unfortunately, with the data analysed, no significance could be attributed to the competition variable, however it is measured, so this insight into the behaviour of airlines on a route is missing. Airport planners can benefit from the partial insight that is provided.

It is unfortunate that in an attempt to rid the selected data of confounding influences that the remaining cases on the north Atlantic that could be selected are so sparse; it is also unfortunate that the results do not pick up the impact of competition even when the UK routes are focussed on in the econometric models. It seems that a different approach to the data might be justified as there are no consistently served routes from French regional airports that can be studied, for example, to either non-hubs in the USA or airports that are not slot constrained. It seems a more rewarding approach would be to study the hubs and slot constrained airports and represent these characteristics with dummy variables. This will tell us how these influences vary between airport type and, of course, the routes to say JFK from a variety of European 
airports will be data rich and illustrate competition. Slot constrained airports are ORD, JFK and LHR whereas unconstrained hubs are CDG, AMS, DFW and ATL. In addition, if the interest is in airline behaviour, it may be better to focus on data for a single representative airline over time. 


\section{References}

Belsley, D.A., (1988). Two- or three stage least squares?, Computer Science in Economics and Management 1, 21-30.

Brueckner, J.K. and Zhang, Y. (2001) A Model of Scheduling in Airline Networks: How a hub-and-spoke system affects flight frequency, fares and welfare. Journal of Transport Economics and Policy, 35, 195-222.

Bureau of Transportation Statistics, Database Name: Air Carrier Statistics (Form 41 Traffic) - All Carriers T-100 International Segment.

Button, K and Drexler J. (2005), Recovering Costs by Increasing Market Share: An empirical critique of the S-Curve, Journal of Transport Economics and Policy, 39, $391-404$

Givoni, M. and Rietveld, P. (2007) Choice of Aircraft Size: Explanations and Implications. Paper presented at $10^{\text {th }}$ Annual World Conference of the Air Transport Research Society, University of California at Berkeley, 21-24 June, 2007.

Givoni, M. and Rietveld, P. (2009) The Environmental implications of airlines' Choice of Aircraft Size, Journal of Air Transport Management, xx,X-Xx.

Greene, W.H., (2003). Econometric analysis, New York: Prentice Hall, $5^{\text {th }}$ Ed.

Gujarati, D.N., (2003), Basic Econometrics, McGraw Hill, $4^{\text {th }}$ Ed.

Janic, M., 1997, Liberalisation of European Aviation: Analysis and modelling of the airline behaviour, Journal of Air Transport Management, 4, 167-180.

Mason, K.J. (2007), Airframe Manufacturers: Which has a better view of the future?, Journal of Air Transport Management, 13, 9-15. 
Pitfield, D.E. (2005) Some Speculations and Empirical Evidence on the Oligopolistic

Behaviour of Competing Low-Cost Airlines, Journal of Transport Economics and Policy, 39, 379-390.

Pitfield, D.E. (2007) Ryanair’s Impact on Airline Market Share from the London Area Airports: A time series analysis, Journal of Transport Economics and Policy, 41, 7592.

Pitfield, D.E. and Caves, R.E. (2000a) Airline Strategies for Aircraft Size and Airline Frequency with changing Demand and Competition: A Two-Stage Least Squares Analysis for short haul traffic. Paper presented to the $6^{\text {th }}$ World Congress of the Regional Science Association International, Lugano, Switzerland, 16-20 May, 2000. Pitfield, D.E. and Caves R.E. (2000b) Airline Strategies for Aircraft Size and Airline Frequency with changing Demand and Competition: A Two-Stage Least Squares Analysis for long haul traffic on the North Atlantic. Paper presented to the $40^{\text {th }}$ European Congress of the Regional Science Association International, Barcelona, Spain, 30 August - 2 September, 2000.

Ramsey, J.B., (1969), tests for Specification Errors in Classical Linear Least Squares Regression Analysis, Journal of the Royal Statistical Society B, 32, 350-371.

STATA, 2006, Statistical data analysis (STATA) user’s manual, Texas, StataCorp LP.

Stiglitz, J.E. (1993), Economics, W.W.Norton. New York.

Wei, W. and Hansen, M. (2005) Impact of Aircraft Size and Seat Availability on Airlines’ Demand and Market Share in Duopoly Markets, Transportation Research E, 41, 315-327.

Wooldridge, J.M., (2002), Econometric analysis of cross section and panel data, MIT press. 